\title{
Numerical Studies of Adherend Thickness Influence on the Response of Single Lap Joint under Longitudinal Load
}

\author{
Jianguang Zhang ${ }^{1,}$, Xiaodong He $\mathrm{H}^{1, \mathrm{~b}}$, Wenbo Liü ${ }^{1, \mathrm{c}}$, Rongguo Wang ${ }^{1, \mathrm{~d}}$ \\ ${ }^{1}$ Center for Composites and Structure, Harbin Institute of Technology, Harbin 150001, China \\ azhangjg@hit.edu.cn, bhexd@hit.edu.cn, ${ }^{\mathrm{C}}$ liuwenbo@hit.edu.cn, ${ }^{\mathrm{d}}$ wrg@hit.edu.cn
}

Keywords: Adhesive bonding; Lap joint; Adherend thickness; Stress distribution

Abstract. In this paper, a finite element model was developed to investigate the response of adhesively bonded joint under tensile load. Different adherend thicknesses were chosen to evaluate its influence on the stress state in the adhesive film. The results showed that adherend thickness have a significant influence on the stress state of the bond area. With adherend thickness increased from $2.5 \mathrm{~mm}$ to $4 \mathrm{~mm}$, both maximum shear and peel stress at the edges of the joint diminished. The decrease of stresses was due to the higher stiffness with thicker adherent.

\section{Introduction}

Adhesive bonding technique has been widely applied in composite structures with main advantages of high structural efficiency and distribution load over a much larger area than mechanical joints $^{[1]}$. In past decades, many research have carried out to study mechanical behavior of single lap joint. In an ideal case, stresses are expected to be uniform through the bond area. However, in reality, stresses including in-plane shear stress and peel stress normal to the load direction, always concentratd at the edges of lap joint. Such stress states are very important in the failure process. There are many parameters that affect the stresses in the joints, including overlap length ${ }^{[2-3]}$, properties of adherend and adhesive ${ }^{[4-5]}$, and thickness of adhesive and adherend ${ }^{[6-7]}$.

The primary aim of this paper is to investigae, using finite element analysis, the effect of adherend thickness on stress state of adhesive in single lap joint with adherend couples of composites to composites.

\section{Finite element model}

The stress distribution in the adhesive film of lap joint was modeled by means of static analysis with Nastran software. The geometry of the joint has adherends with length of $100 \mathrm{~mm}$, width of 25 $\mathrm{mm}$, and an overlap length of $12.5 \mathrm{~mm}$. Four differnt adherend thicknesses, $2.5 \mathrm{~mm}, 3.0 \mathrm{~mm}, 3.5 \mathrm{~mm}$, and $4 \mathrm{~mm}$, were selected. The thickness of the adhesive layer was chosen as $0.15 \mathrm{~mm}$. The adherend and adhesive were modeled using an eight-node solid element. The element size in the lap-joint was refined, whereas a relatively coarser element size was used in the adherents, as shown in Fig. 1. This was done to improve the results while keeping the model size as small as possible to reduce computational and postprocessing times. Two spacers were applied to ensure that tensile direction was parallel to the bond interface. 


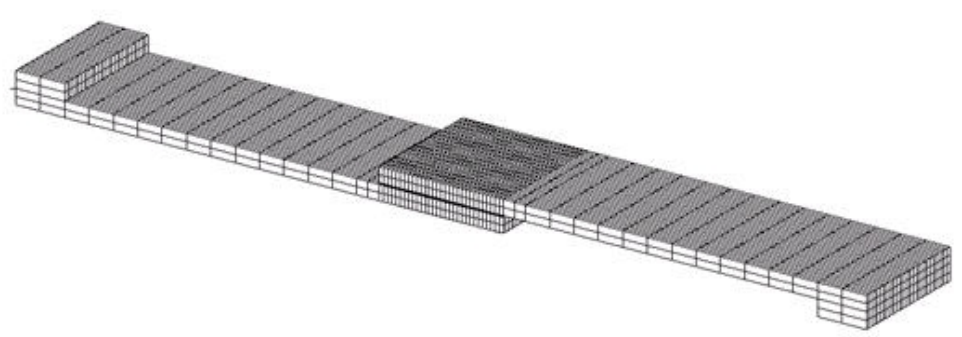

Fig. 1 Finite element model of lap joint.

The composites adherend was treated as a linear elastic orthotropic solid in this model. The adhesive was treated as a linear elastic isotropic solid. In case of tension of the joint, one end of the adherent was constrained from $\mathrm{x}, \mathrm{y}$, and $\mathrm{z}$ translations, and the other end was constrained from $\mathrm{y}$ and $\mathrm{z}$ translations. A tensile load of $2600 \mathrm{~N}$ was applied to the other end toward positive $\mathrm{x}$ direction. The input material data are given in Table 1. The output of analysis included stress and displacement of lap joint.

Table 1 Input data of adherent and adhesive.

\begin{tabular}{llcc}
\hline Material & Property & & \\
\hline & $\mathrm{E}_{11}=82 \mathrm{GPa}$ & $\mathrm{E}_{22}=82 \mathrm{GPa}$ & $\mathrm{E}_{33}=9 \mathrm{GPa}$ \\
Adherent & $\mathrm{G}_{12}=5.7 \mathrm{GPa}$ & $\mathrm{G}_{13}=4 \mathrm{GPa}$ & $\mathrm{G}_{23}=4 \mathrm{GPa}$ \\
& $=0.25$ & $=0.3$ & $=0.3$ \\
Adhesive & $\mathrm{E}=2.8 \mathrm{GPa}$ & $=0.35$ & \\
\hline
\end{tabular}

\section{Results and discussion}

Displacement of adhesive film. The displacement of lap joint is illustrated in Fig. 2. When the lap joint was subjected to a longitudinal tensile load, adherend couples deformed like a wavy shape. The bond interface deflected from its origienal position parallel to the load direction. As a result, the stresses in the adhesive film were not uniform and stress concentration occured. The calculated displacements of adhesive film of lap joint with different adherend thickness are presented in Table 2. Both displacements of adhesive in longitudinal and thickness direction decreased with adherend thickness increased from $2.5 \mathrm{~mm}$ to $4 \mathrm{~mm}$.

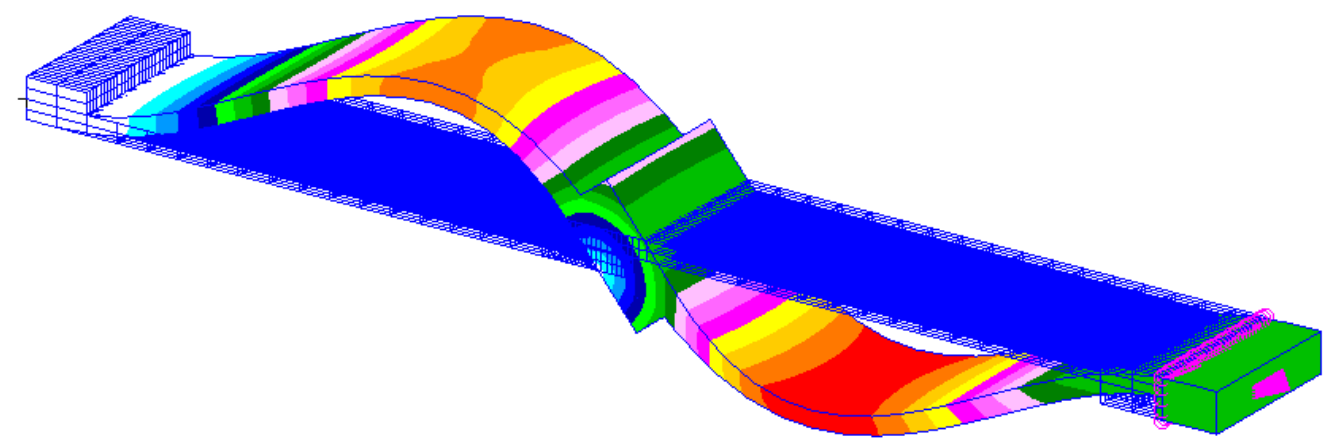

Fig. 2 Deformation of lap joint under tensile load (adherent thickness of 3mm). 
Table 2 Displacements of adhesive film in the lap joint with different adherend thickness.

\begin{tabular}{lllcl}
\hline \multirow{2}{*}{ Displacement (mm) } & \multicolumn{4}{c}{ Adherent thickness (mm) } \\
& 2.5 & 3 & 3.5 & 4 \\
\hline In longitudinal direction & 0.0887 & 0.074 & 0.0608 & 0.0562 \\
In thickness direction & 0.154 & 0.107 & 0.0789 & 0.0608 \\
\hline
\end{tabular}

Stress distribution. The shear and peel stress distribution in the adhesive film of adherend couples with different thickness are illustrated in Fig.3 and Fig.4, respectively. Both maximum shear and peel stresses occured at the joint edges, as expected. The shear stress, which peaks at the edges, diminished toward the center of the joint. The peel stress distribution showed a steep drop from the joint edges. At the edges of the joint, the adhesive was subjected to tension, which contributed to failure of the adhesive under loading. The tensile peel stress changed to a slightly compression stress toward the center of the lap joint. The difference in stress distribution with various adherend thickness was attributed by the differnt deflection of the adhesive film.

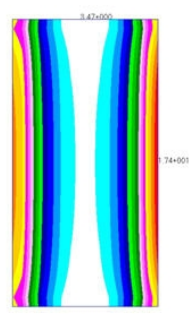

(a)

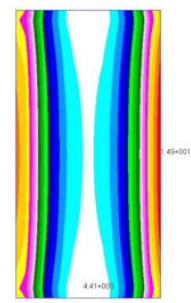

(c)
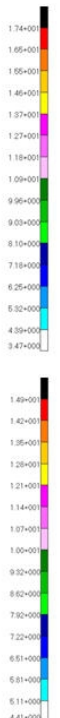

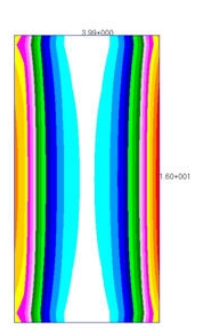

(b)

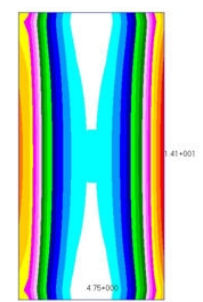

(d)
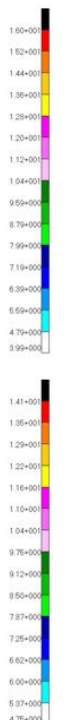

Fig. 3 Shear stress distribution in the adhesive film of lap joint with four different adherend thicknesses. (a) $2.5 \mathrm{~mm}$; (b) $3 \mathrm{~mm}$; (c) $3.5 \mathrm{~mm}$; (d) $4 \mathrm{~mm}$

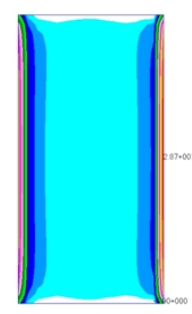

(a)

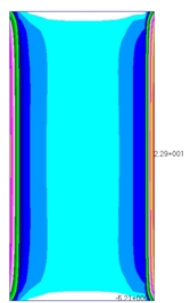

(c)
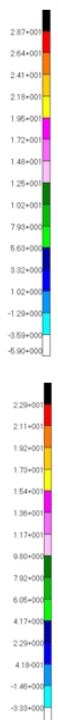

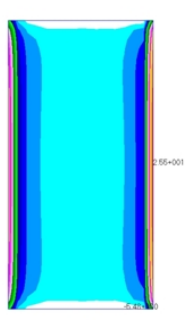

(b)

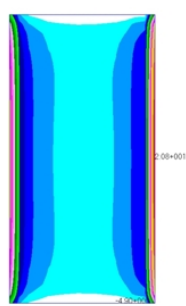

(d)
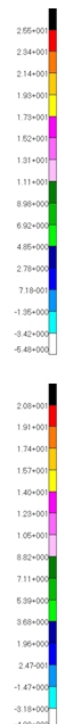

Fig. 4 Peel stress distribution in the adhesive film of lap joint with four different adherend thicknesses.

(a) $2.5 \mathrm{~mm}$; (b) $3 \mathrm{~mm}$; (c) $3.5 \mathrm{~mm}$; (d) $4 \mathrm{~mm}$ 
Effect of adherend thickness. The adherend thickness influence on maximum and minimum shear strength is illustrated in Fig.5. With adherend thickness increased from $2.5 \mathrm{~mm}$ to $4 \mathrm{~mm}$, the maximum shear stress in adhesive decreaed. However, the minimum shear stress, occured in the center of the joint, increased with increasing adherend thickness. This indicated that shear stress distributed more evenly through the bond area. The adherend thickness influence on maximum peel stress and displacement of adhesive in thickness direction is illustrated in Fig.6. Simillar to shear stress, maximum peel stress decreased with increasing adherend thickness. The effect of adherend thickness can be explained in terms of displacement in the adhesive film. Simply stated, thicker adherend increase the stiffness of lap joint and favor a plane stress state duing to the smaller displacement of adhesive film. In the case of pure shear, stresses distributed uniformly through the bond area since there is no deflection of adhesive.

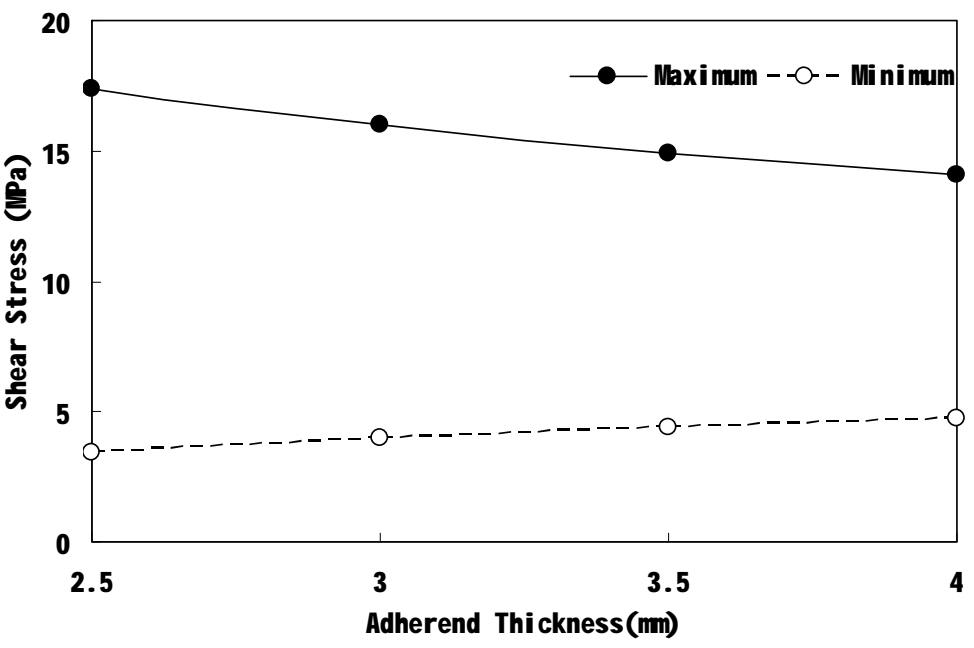

Fig. 5 Effect of adherend thickness on the shear stress in the adhesive film.

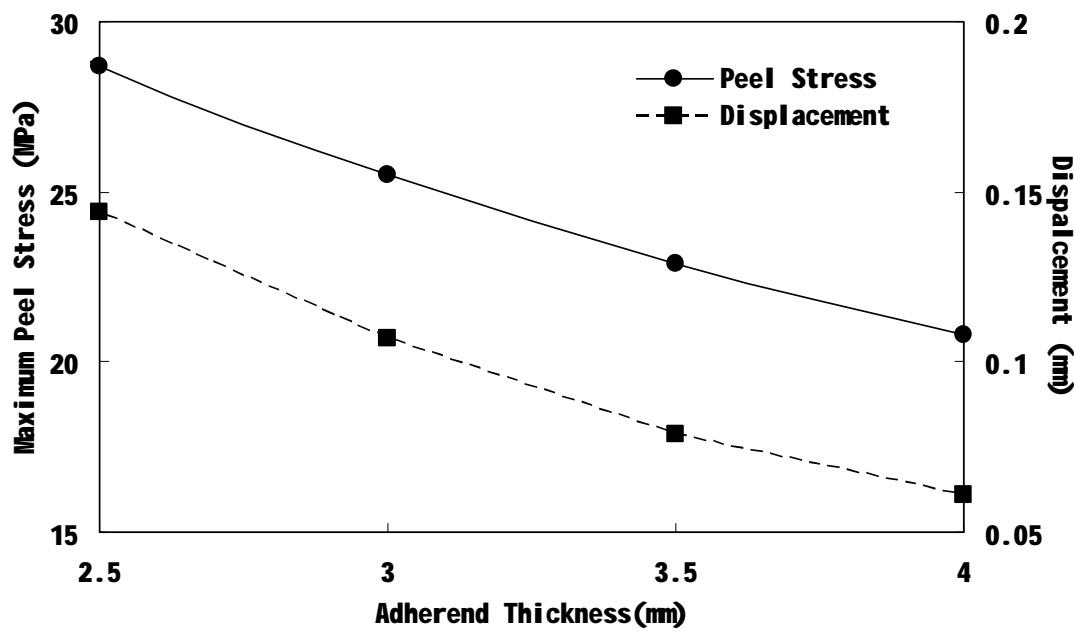

Fig. 6 Effect of adherend thickness on the peel stress and displacement of adhesive film in thickness direction.

\section{Conclusions}

Effect of adherend thickness on the stress distribution of adhesive in lap joint was investigated by finite element analysis. The results showed that both shear and peel stresses peaked at the edges of joint. Shear stress diminished toward to the center of the joint. With increasing adherend thickness, the degree of shear stress concentration was relieved with lower maximum value and higher minimum 
value. Thicker adherent increased the stiffness of joint, resulting in an lower peel stress at the edges of lap joint, which can be explained by smaller displacement of adhesive in thickness direction.

\section{References}

[1] Ageorges C, Ye L, Hou M. Composites Part A 2001;32A:839-64.

[2] Czanocki P, Piekarski K. Int J Adhes Adhes 1986;6:93-5.

[3] Mazumdar SK, Malick PK. Polym Compos 1998;19:136-46.

[4] Sawa T, Liu J, Nakano K, Tanaka J. J Adhes Sci Technol 2000;14:43-66.

[5] Kiu J, Sawa T, Toratani H. J Adhes 1999;69:43-66.

[6] Vinson JR. Polym Eng Sci 1989;29:1325-31.

[7] da Silva LFM, Carbas RJC, Critchlow GW, Figueiredo MAV, Brown K. Int J Adhes Adhes 2009;29:621-32. 